\title{
Assessment of Remogliflozin Etabonate, a Sodium-Dependent Glucose Co-Transporter-2 Inhibitor, as a Perpetrator of Clinical Drug Interactions: A Study on Drug Transporters and Metabolic Enzymes
}

\section{Joseph W. Polli*, Joan E. Humphreys, Kelly A. Harmon, Lindsey O. Webster, Mindy J. Reese and Christopher C. MacLauchlin} GlaxoSmithKline Inc, Research Triangle Park, NC, USA

\begin{abstract}
Type 2 diabetes mellitus is a chronic disease characterized by progressive deterioration of glycemic control and an increased risk of associated complications. Remogliflozin etabonate is the ester prodrug of remogliflozin, a selective sodium-dependent glucose transporter-2 inhibitor that was under development to treat type 2 diabetes. This work investigated the in vitro inhibition of efflux and uptake transporters and cytochrome P450 enzymes by remogliflozin etabonate, remogliflozin and a number of other metabolites. As well, the ability of remogliflozin to induce cytochrome P450 enzymes in human hepatocytes was examined. Remogliflozin etabonate, remogliflozin and GSK279782 (an active pharmacological metabolite of remogliflozin) were inhibitors of organic anion transporting polypeptide-1B1 with $\mathrm{IC}_{50}$ values of 5.3, 25 and $14 \mu \mathrm{M}$, respectively. Remogliflozin etabonate and remogliflozin were inhibitors of organic cation transporter-1 with $\mathrm{IC}_{50}$ values of 43 and $39 \mu \mathrm{M}$, respectively. In contrast, remogliflozin etabonate, remogliflozin, GSK279782, and GSK333081 (a metabolite of remogliflozin) were not inhibitors of P-glycoprotein, a number of other renal transporters, or cytochrome P450 enzymes. Further, three circulating glucuronide metabolites found in human plasma were not inhibitors of cytochrome P450 enzymes or organic anion transporters. Remogliflozin etabonate, but not remogliflozin or GSK279782, activated the pregnane X Receptor in vitro. Further studies demonstrated that remogliflozin (up to $100 \mu \mathrm{M}$ ) did not induce cytochrome P450 3A4 or 1A1 mRNA in human hepatocytes; however a small increase was noted for CYP2B6 mRNA. Combined with pharmacokinetic data from healthy volunteers and diabetic subjects, these in vitro investigations provide a low drug interaction potential for remogliflozin etabonate, remogliflozin and the associated metabolites to be perpetrators of clinical drug interactions. This information has been used to guide the design of clinical studies with remogliflozin etabonate when given with other co-medications.
\end{abstract}

Keywords: Diabetes; SGLT2 inhibitors; Transporters; Drug interactions; Cytochrome P450 enzymes

Abbreviations: Pgp: P-glycoprotein; MDCK: Madin Darby Canine Kidney cells; IC50: Concentration required for 50\% Inhibition; SGLT2: Sodium-Dependent Glucose Co-transporter-2; UKPDS: United Kingdom Prospective Diabetes Study; ABC: ATP Binding Cassette Family; SLC: Solute Carrier Family; PXR: Pregnane X Receptor

\section{Introduction}

Type 2 diabetes mellitus (T2DM) is a chronic disease characterized by progressive deterioration of glycemic control and an increased risk of associated complications. Evidence from clinical trials suggests that improving glycemic control can substantially reduce the long-term microvascular and macrovascular complications of diabetes [1-3]. Current guidelines recommend that T2DM patients should be initially managed with diet and exercise followed by pharmacological treatment, which typically involves patients taking multiple medications $[4,5]$. Sodium-dependent glucose co-transporter (SGLT) inhibitors are an exciting new class of anti-diabetic agents [6-9]. These drugs act by competitively inhibiting the SGLT proteins, thus blocking intestinal and renal absorption of glucose. Inhibition of SGLTs has been shown to translate to a reduction in plasma glucose concentrations with a low incidence of hypoglycemia [9].

Within the SGLT family of transporters, the SGLT1 and SGLT2 proteins have been active drug targets for over a decade. SGLT1 is a high-affinity, low-capacity glucose/galactose co-transporter primarily expressed in the intestine, which is also expressed at lower levels in the kidney $[10,11]$. In contrast, SGLT2 is a low-affinity, high-capacity glucose transporter that is specifically expressed in the renal proximal tubule at high levels. Of the approximately $180 \mathrm{~g}$ of plasma glucose filtered and reabsorbed by the kidney each day, the vast majority ( 80 to $90 \%$ ) of the glucose uptake activity is associated with SGLT2, with SGLT1 having a more modest (10-20\%) contribution [9]. Therefore, selective inhibition of SGLT2 has become an attractive drug target $[10,12,13]$. Indeed, it has been clearly demonstrated in numerous clinical studies that pharmacological inhibition of SGLT2 results in glucosuria, which leads to reductions in post-prandial and fasting plasma glucose concentrations $[8,13]$.

Remogliflozin etabonate (GSK189075; KGT-1681) is the prodrug of remogliflozin (GSK189074; KGT-1650), the active entity that inhibits SGLT2 [14,15]. Remogliflozin is a potent and selective SGLT2 inhibitor with an in vitro $\mathrm{IC}_{50}$ value of $12.4 \mathrm{nM}$ [15]. Oral administration of remogliflozin etabonate reduced postprandial glucose excursions without inducing hypoglycemia, improved plasma glucose concentrations in subjects with diabetes, and reduced glycosylated hemoglobin (HbA1c) levels [14]. The objective of this work was to investigate the in vitro

*Corresponding author: Joseph W. Polli, Preclinical Drug Metabolism and Pharmacokinetics, GlaxoSmithKline, Inc, P.O. Box 13398, Room: N1.407, Research Triangle Park, NC 27709, USA, Tel: (919) 483-3221; Fax: (919) 483-0443; E-mail: joseph.w.polli@gsk.com

Received May 20, 2012; Accepted June 25, 2012; Published June 30, 2012

Citation: Polli JW, Humphreys JE, Harmon KA, Webster LO, Reese MJ, et al. (2012) Assessment of Remogliflozin Etabonate, a Sodium-Dependent Glucose Co-Transporter-2 Inhibitor, as a Perpetrator of Clinical Drug Interactions: A Study on Drug Transporters and Metabolic Enzymes. J Diabetes Metab 3:200. doi:10.4172/2155-6156.1000200

Copyright: ( 2012 Polli JW, et al. This is an open-access article distributed under the terms of the Creative Commons Attribution License, which permits unrestricted use, distribution, and reproduction in any medium, provided the original author and source are credited. 
Citation: Polli JW, Humphreys JE, Harmon KA, Webster LO, Reese MJ, et al. (2012) Assessment of Remogliflozin Etabonate, a Sodium-Dependent Glucose Co-Transporter-2 Inhibitor, as a Perpetrator of Clinical Drug Interactions: A Study on Drug Transporters and Metabolic Enzymes. J Diabetes Metab 3:200. doi:10.4172/2155-6156.1000200

Page 2 of 8

inhibition of efflux/uptake transporters and cytochrome P450 (CYP) enzymes, and the potential impact of remogliflozin etabonate, remogliflozin and metabolites to cause drug interactions. From these in vitro and in vivo investigations, a mechanistic basis for elucidating potential clinical drug interactions has been developed to guide the design of future clinical studies with remogliflozin etabonate.

\section{Materials and Methods}

\section{Materials}

GlaxoSmithKline Chemical Development supplied $\left[{ }^{14} \mathrm{C}\right]-$ remogliflozin etabonate ( $55-57 \mathrm{mCi} / \mathrm{mmol}$ ), remogliflozin etabonate, remogliflozin, GSK279782 (a pharmacologically active metabolite), GSK333081 (metabolite), GSK1997711 (glucuronide metabolite), GSK1997714 (glucuronide metabolite), GSK355993 (glucuronide metabolite) and GF120918 (Elacridar). [G- $\left.{ }^{3} \mathrm{H}\right]$-digoxin $(5 \mathrm{Ci} / \mathrm{mmol}),\left[{ }^{3} \mathrm{H}\right]$-estradiol $17 \beta$-D-glucuronide $(45.0 \mathrm{Ci} / \mathrm{mmol}),[14 \mathrm{C}]-p$-Aminohippuric acid $(53$ $\mathrm{mCi} / \mathrm{mmol}),\left[{ }^{3} \mathrm{H}\right]$-prostaglandin $\mathrm{F} 2 \alpha(155 \mathrm{Ci} / \mathrm{mmol}),\left[{ }^{3} \mathrm{H}\right]$-estrone sulfate $(57 \mathrm{Ci} / \mathrm{mmol})$, and $\left[{ }^{3} \mathrm{H}\right]$-histamine $(18 \mathrm{Ci} / \mathrm{mmol})$ were supplied by Perkin Elmer Life Sciences (Boston, MA). $\left[{ }^{14} \mathrm{C}\right]$-Tetraethylammonium $(55 \mathrm{mCi} / \mathrm{mmol})$ was purchased from American Radiolabeled Chemicals (St. Louis, MO) and $\left[{ }^{14} \mathrm{C}\right]$-uric acid $(52 \mathrm{mCi} / \mathrm{mmol})$ was purchased from Moravek Biochemicals (Brea, CA). Ethoxyresorufin (ER) was purchased from Biomol (Plymouth Meeting, PA) and 7-benzyloxyquinoline (7BQ) was purchased from BD Biosciences (Henshaw, MA). Cell culture reagents were purchased from Invitrogen (Carlsbad, CA). All other reagents were purchased from Sigma-Aldrich (St Louis, MO). Transwells (12-well, $11-\mathrm{mm}$ diameter, $0.4 \mu \mathrm{m}$ pores) were purchased from Corning Costar (Cambridge, MA).

\section{Pgp inhibition assays}

Cell culture and transport inhibition studies were completed as described [16] using the MDCKII-MDR1 cell line. Remogliflozin etabonate, remogliflozin, and selected metabolites were tested in triplicate at a minimum of six concentrations spanning 0.1 to 100 $\mu \mathrm{M}$ for Pgp inhibition. Inhibition studies were conducted for $90 \mathrm{~min}$ using $\left[{ }^{3} \mathrm{H}\right]$-digoxin $(27 \mathrm{nM})$ as the probe substrate. $\left[{ }^{3} \mathrm{H}\right]$-Digoxin was quantified by liquid scintillation counting (LSC) by using a $2900 \mathrm{TR}$ liquid scintillation counter (Packard Instrument Company; Downers Grove, IL). GF120918 was used as a positive control inhibitor.

\section{OATP, OAT, OCT and URAT inhibition assays}

Cell culture and transport inhibition studies were completed as described previously [17]. For OATP1B1 studies, a Chinese Hamster Ovary cell line heterologously expressing the human OATP1B1 transporter (CHO-OATP1B1) was obtained from the University of Zurich (Zurich, Switzerland). CHO-OATP1B1 cells were seeded into 24-well assay plates (Becton Dickinson, Franklin Lakes, NJ) at a density of 50000 cells $/ \mathrm{cm} 2$ in cell culture medium (Dulbecco's Modified Eagle Medium with Glutamax (DMEM), 10\% (v/v) fetal bovine serum, $0.5 \%$ (v/v) penicillin/streptomycin 10000 units $/ \mathrm{mL}, 0.1 \%(\mathrm{v} / \mathrm{v})$ L-proline 50 $\mathrm{mg} / \mathrm{mL}$ and $0.7 \%(\mathrm{v} / \mathrm{v})$ Geneticin $50 \mathrm{mg} / \mathrm{mL}$ ). The monolayers were used 2 days post seeding and induced for at least 24 hours prior to use with $5 \mathrm{mM}$ sodium butyrate. For inhibition studies, CHO-OATP1B1 monolayers were preincubated $\left(37^{\circ} \mathrm{C}\right)$ for 15 to 30 minutes in $1 \mathrm{~mL}$ transport medium (Dulbecco's Phosphate Buffered Saline (DPBS) plus $1 \%$ DMSO) with or without remogliflozin etabonate, remogliflozin, metabolites or rifamycin (positive control inhibitor). Following removal of preincubation solution, $400 \mu \mathrm{L}$ of transport medium

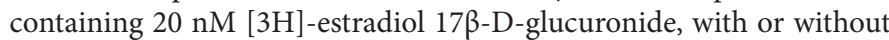
inhibitors, was added and the cells incubated at $37^{\circ} \mathrm{C}$ for 5 minutes. The inhibitor solution was removed, cells rinsed three times using $800 \mu \mathrm{L}$ cold $\left(4^{\circ} \mathrm{C}\right)$ DPBS, cells lysed with $400 \mu \mathrm{L}$ of $1 \%(\mathrm{v} / \mathrm{v})$ Triton X-100 and radioactivity quantified by LSC.

OAT, OCT and URAT inhibition screening studies were completed at Fuji Biomedix Co. Ltd. (Yamanashi, Japan). For OAT and OCT inhibition assays, transporter expressing S2 cells were seeded at a cell density of $10^{5}$ cells/well in 24-well tissue culture plates individually expressing either OAT1, OAT2, OAT3, OAT4, OCT1, OCT2, OCT2-A, or OCT3; the parental S2 cell line is derived from the S2 portion of the renal proximal tubules and carries a temperature-sensitive simian virus 40 large T-antigen gene [18]. For URAT inhibition assays, transporter expressing HEK-293 cells were seeded in 24-well Biocoat plates (Becton Dickinson, Franklin Lakes, NJ) at a cell density of $10^{5}$ cells/well. Transporter expressing cells were cultured for 2 days at $33^{\circ} \mathrm{C}$ (S2 cells) or $37^{\circ} \mathrm{C}$ (HEK293 cells) as described [18]. Remogliflozin etabonate, remogliflozin, metabolites and positive control inhibitors (probenecid, quinidine and benzbromarone for OATs, OCTs, and URAT1, respectively) were dissolved in DMSO and then diluted to a final concentration of $30 \mu \mathrm{M}$ into uptake medium (DPBS pH 7.5 for S2 cells or Hank's balanced salt solution (HBSS) pH 7.4 containing no Clfor HEK293 cells) containing the radiolabeled substrates. Monolayers were incubated for $2 \mathrm{~min}$ (OAT1, OAT3 and OAT4), $0.5 \mathrm{~min}$ (OAT2), $15 \mathrm{~min}$ (OCT1), $5 \mathrm{~min}$ (OCT2 and OCT2-A), $1 \mathrm{~min}$ (OCT3) or $5 \mathrm{~min}$ (URAT1). After incubation, the solution was removed and uptake stopped by adding ice-cold DPBS (or HBSS). Cells were lysed with 0.1 $\mathrm{M}$ sodium hydroxide, lysate collected and radioactivity determined by LSC. Protein concentrations of cellular lysates were determined using a BCA Protein Assay Reagent (Pierce, Rockford, IL) as described by the manufacturer.

\section{CYP inhibition assays}

The inhibition of CYP enzymes (CYP 1A2, 2A6, 2B6, 2C8, 2C9, 2C19, 2D6 and 3A4) by remogliflozin and GSK279782 was assessed in human liver microsomes (pool of 16 individuals; XenoTech LLC, Lenexa, Kansas) using LC/MS based methods as described [19,20], while the metabolites (GSK333081, GSK1997711, GSK1997714, GSK355993) were assessed in recombinant (CYP 1A2, 2C9, 2C19, 2D6 and 3A4) enzymes (bactosomes, $10 \mathrm{mg} / \mathrm{mL}$; XenoTech LLC) using fluorescence based methods as described below.

Human liver microsomes: The ability of remogliflozin or GSK279782 to inhibit CYP enzymes in a direct and metabolismdependent manner was investigated with a pool of human liver microsomes $[19,20]$. Duplicate incubations $(250 \mu \mathrm{L})$ were conducted at $37^{\circ} \mathrm{C}$ containing potassium phosphate buffer $(50 \mathrm{mM}, \mathrm{pH} 7.4)$, an NADPH-generating system (1.7 mg NADP+, $7.8 \mathrm{mg}$ glucose-6phosphate, and 6 units of glucose-6-phosphate dehydrogenase per $\mathrm{mL})$, human liver microsomes $(0.1 \mathrm{mg} / \mathrm{mL})$, inhibitor (or solvent) and probe substrate at approximately the $\mathrm{Km}$. The probe substrates were: CYP 1A1- phenacetin; 2A6 - coumarin; 2B6 - buproprion; 2C8 rosiglitazone; 2C9 - diclofenac; 2C19 - mephenytoin; 2D6 - bufuraol; 3A4 - atorvastatin, midazolam, and nifedipine. Reactions were initiated by addition of the NADPH regenerating system after pre-warming at $37^{\circ} \mathrm{C}$ for 5 minutes to assess direct inhibition. To examine metabolismdependent inhibition, remogliflozin, GSK279782, or positive control inhibitor were preincubated at $37^{\circ} \mathrm{C}$ with human liver microsomes and an NADPH-generating system for 20 minutes. After the preincubation period, the probe substrate was added, and the incubation continued for 5 or $10 \mathrm{~min}$. Known direct and metabolism-dependent inhibitors were included as positive controls [19]. Reactions were terminated by the addition of $250 \mu \mathrm{L}$ acetonitrile, centrifuged to remove protein, 
Citation: Polli JW, Humphreys JE, Harmon KA, Webster LO, Reese MJ, et al. (2012) Assessment of Remogliflozin Etabonate, a Sodium-Dependent Glucose Co-Transporter-2 Inhibitor, as a Perpetrator of Clinical Drug Interactions: A Study on Drug Transporters and Metabolic Enzymes. J Diabetes Metab 3:200. doi:10.4172/2155-6156.1000200

Page 3 of 8

spiked with an internal standard and analyzed by LC-MS/MS on a Sciex API3000 or equivalent using a validated method for the detection of probe substrate metabolites. Analyte/internal standard peak area ratios and the metabolite concentrations were determined by interpolation from the appropriate standard curve. Rates of metabolite production at each concentration of remogliflozin, GSK279782, or positive control inhibitor, were expressed as a percentage of the mean uninhibited control rate for each assay.

Recombinant: Duplicate $(250 \mu \mathrm{L})$ incubations were conducted at $37^{\circ} \mathrm{C}$ containing potassium phosphate buffer $(50 \mathrm{mM}, \mathrm{pH} 7.4)$, an NADPH-generating system (1.7 mg NADP+, $7.8 \mathrm{mg}$ glucose-6-phosphate, and 6 units of glucose-6-phosphate dehydrogenase per $\mathrm{mL}$ ), recombinant enzyme $(0.1 \mathrm{mg} / \mathrm{mL})$, inhibitor (or solvent) and probe substrate at approximately the $\mathrm{Km}$. The probe substrates were: CYP $1 \mathrm{~A} 2$ ethoxyresorufin; 2C9 - 7-methoxy-4-trifluromethylcoumarin-3-acetic acid; 2C19 - 3-butyryl-7-methoxycoumarin; 2D6 - 4-methylaminomethyl-7-methoxycoumarin; 3A4 - diethoxyfluorescein and 7-benzyloxyquinoline

Reactions were initiated by addition of the NADPH regenerating system after pre-warming at $37^{\circ} \mathrm{C}$ for 10 minutes. GSK1997711, GSK1997714 or GSK355993 were tested at final concentrations of up to $300 \mu \mathrm{M}$ and GSK333081 up to $100 \mu \mathrm{M}$. Incubations with miconazole were used to confirm an appropriate inhibition response. The probe substrates (with the exception of ER and 7BQ) were designed based on reported CYP structure activity relationships and synthesized in-house at GlaxoSmithKline [International Patent Application WO 00/22159, 2000; WO 02/12542, 2002; WO 99/58710, 1999; WO 01/44495, 2001]. The incubation plate was analyzed using a fluorescence plate reader with the excitation and emission wavelengths optimized for each of the metabolites derived from the probe substrate. SoftMax Pro (v3.1.2, Molecular Devices, Sunnyvale CA) calculated the change of fluorescence intensity over 10 scan cycles and expressed the results as the rate (slope). The percentage of remaining enzyme activity was determined using Excel (v. 2002 SP3); the rate of the vehicle control (solvent only) was set at $100 \%$. Rates of metabolite production at each concentration of inhibitor were expressed as a percentage of the mean uninhibited control rate for each assay.

\section{PXR activation assay}

Cell culture and pregnane $\mathrm{X}$ receptor (PXR) activation studies were completed as described [21]. HuH7 cells were seeded onto 96 well microtitre plates at a seeding density of 180,000 cells $/ \mathrm{mL}$ (each well received 18,000 cells) and plates incubated overnight at $37^{\circ} \mathrm{C}$. The next day, cells were transfected with a human PXR/SPAP reporter gene and $\beta$-galactosidase to correct for transfection efficiency. On day three, remogliflozin etabonate, remogliflozin, GSK279782 (eleven concentrations covering 0.01 to $10 \mu \mathrm{M}$ ) or rifampicin (positive control run at $10 \mu \mathrm{M}$ ) were added and plates incubated overnight. Following incubation with test article, the wells were assayed for SPAP and $\beta$-galactosidase activity. Approximately $50 \mu \mathrm{L}$ supernatant per well was transferred to a clean plate containing $200 \mu \mathrm{L}$ of either SPAP buffer $(1.86$ $\mathrm{mg} / \mathrm{mL}$ p-Nitrophenyl phosphate, $0.106 \mathrm{~mL} / \mathrm{mL}$ diethanolamine, 16.36 $\mathrm{mg} / \mathrm{mL} \mathrm{NaCl}, 0.102 \mathrm{mg} / \mathrm{mL} \mathrm{MgCl}_{2}$ in water, $\mathrm{pH}$ 9.85) or $\beta$-galactosidase substrate buffer $(1.1 \mathrm{mg} / \mathrm{mL}$ o-Nitrophenyl $ß$-D-Galactopyranoside in $0.1 \mathrm{M} \mathrm{NaHPO}$, pH 7.2 with $0.125 \%$ Triton-X 100). Samples were incubated at $37^{\circ} \mathrm{C}$ for 30 to 45 minutes for color development and absorbance was measured at $405 \mathrm{~nm}$.

\section{Induction of CYP mRNA in human hepatocytes}

Primary human hepatocytes were obtained commercially, and plated in a sandwich configuration on a collagen substratum with Matrigel overlay (Invitrogen, Carlsbad, CA). Hepatocytes were treated with remogliflozin, positive control inducers or $0.1 \%$ DMSO dissolved in Modified Chee's Medium (MCM) for 48 hours. After the treatment period, cells were harvested with 1:1 mixture of RLT (Qiagen, Valencia, CA) and TRIZOL (1:1) (Invitrogen, Carlsbad, CA) and stored at $-80^{\circ}$ until analysis. Total RNA was extracted from hepatocytes by column extraction using a Qiagen RNeasy 96 RNA extraction kit (Qiagen, Valencia, CA). Following extraction, samples were DNase treated and quantified using a Ribogreen ${ }^{\bullet}$ RNA quantitation kit (Molecular Probes, Eugene, OR), and cDNA was synthesized using Superscript $\mathrm{II}^{\mathrm{si}}$ RNase $\mathrm{H}$ - reverse transcriptase (Invitrogen, Carlsbad, CA). The resultant cDNA template was used to quantify the number of copies of mRNA for selected CYP genes using an ABI 7900 Sequence Detection System (Applied Biosystems Inc., Foster City, CA). Serially diluted human genomic DNA was used as a standard for determining the relative copy number of each CYP gene. The resulting copy numbers were normalized to the total RNA concentration, and the fold change of treated samples compared to vehicle control treated samples was calculated. Sequences of primers and probes used in TaqMan assay were:

\begin{tabular}{|l|l|l|l|}
\hline Gene & Forward Primer & Probe & Reverse Primer \\
\hline CYP1A2 & $\begin{array}{l}\text { AGCACGCCCGCT- } \\
\text { GTGA }\end{array}$ & $\begin{array}{l}\text { CATGTCCAGGC- } \\
\text { GCGGCTGC }\end{array}$ & $\begin{array}{l}\text { GGT- } \\
\text { GTCTTCTTCAGTT- } \\
\text { GATGGAGAA }\end{array}$ \\
\hline CYP2B6 & $\begin{array}{l}\text { TCCCCGCCTCTG- } \\
\text { TAGACAAT }\end{array}$ & $\begin{array}{l}\text { CTCTGACTCCCC- } \\
\text { GCAACTTCCT }\end{array}$ & $\begin{array}{l}\text { CTGGCTTGTAGCAG- } \\
\text { GTCTCTCA }\end{array}$ \\
\hline CYP3A4 & $\begin{array}{l}\text { TCTGGTGTTCTCAG- } \\
\text { GCACAGA }\end{array}$ & $\begin{array}{l}\text { CGGTGC- } \\
\text { CATCCCTTGACT- } \\
\text { CAACCT }\end{array}$ & $\begin{array}{l}\text { CAACCAGAAAAACCC- } \\
\text { GTTCACACACAT- }\end{array}$ \\
\hline GAPDH & $\begin{array}{l}\text { CAAGGTCATCCAT- } \\
\text { GACAACTTTG }\end{array}$ & $\begin{array}{l}\text { ACCACAGTCCAT- } \\
\text { GCCATCACTGCCA }\end{array}$ & CAGTCTTCTG \\
\hline
\end{tabular}

\section{Whole-body autoradiography}

All dosing procedures were done according to the approved Institutional Animal Care and Use Committee protocols. The tissue distribution of radioactive drug-related material in the male ListerHooded rats (Charles River Laboratories, UK) following a single oral dose of $25 \mathrm{mg} / \mathrm{kg}$ [14C]-remogliflozin etabonate (formulated in $0.1 \%$ (w/v) 400 cps methylcellulose containing $0.1 \%$ (v/v) Tween 80) was investigated using whole-body autoradiography at $0.25,1,4,24$ hours, 3 days and 28 days hours after dose administration $(n=1$ animal per time point). Tissue processing and image analysis were completed as described [22-24]. Sections were imaged using [14C]-sensitive Fuji imaging plates (BAS-MS, Raytek Scientific Ltd, Sheffield, UK) and the plate scanned (FUJI FLA-5000 radioluminography system, Raytek Scientific Ltd, Sheffield, UK). The resulting images were read and stored using FUJI FLA-5000 Image Reader software version 2 (Raytek Scientific Ltd, Sheffield, UK). Quantification, relative to the standards, was performed using Seescan Densitometry image analysis software (version 1.3 (build 136); Lablogic PLC, Sheffield, UK).

\section{Calculations}

For transporter and CYP inhibition studies, the $\mathrm{IC}_{50}$ values (the concentration of inhibitor required for $50 \%$ inhibition of the monolayer transport, cellular uptake or metabolite production rates) were calculated with GraFit (version 5.06, Erithacus Software Limited, London, UK) using: 
Citation: Polli JW, Humphreys JE, Harmon KA, Webster LO, Reese MJ, et al. (2012) Assessment of Remogliflozin Etabonate, a Sodium-Dependent Glucose Co-Transporter-2 Inhibitor, as a Perpetrator of Clinical Drug Interactions: A Study on Drug Transporters and Metabolic Enzymes. J Diabetes Metab 3:200. doi:10.4172/2155-6156.1000200

Page 4 of 8

$$
y=\frac{\text { Range }}{1+\left(\frac{x}{\mathrm{IC}_{50}}\right)^{s}}+\text { background }
$$

where $y=$ the rate of transport, uptake or metabolite generation of an appropriate probe (expressed as a percentage of the uninhibited control), Range $=$ the rate in the absence of test compound, $s=$ is the slope factor, $x=$ the inhibitor concentration $(\mu \mathrm{M})$, background $=$ the uninhibited rate (expressed as a percentage of the total rate).

PXR activation is expressed as a percentage of that achieved with 10 $\mu \mathrm{M}$ positive control (\% maximum) and is calculated by the following formula:

$$
\% \text { maximum }=\left(\frac{\text { Fold activation by test article }}{\text { Average fold activation of positive control }}\right) * 100
$$

Further, fold activation is given by:

Fold activation $=\left(\frac{\left(\left(\frac{\text { SPAP-SPAP substrate blank average }}{(\beta-\text { Gal })-(\beta-\text { Gal substrate blank average })}\right)-\text { DMSO vehicle average }\right)}{\text { DMSO vehicle average }}\right)$

\section{Results}

\section{Background metabolism of remogliflozin etabonate}

The metabolism of remogliflozin etabonate has been extensively characterized (Figure 1) [25]. This work focused on the potential per- petrator drug interactions that remogliflozin etabonate and its metabolites could have on other therapeutic agents. The rationale for testing of remogliflozin etabonate, remogliflozin and its metabolites in these assays is as follows. Remogliflozin etabonate is a prodrug that is rapidly metabolized by cellular esterases to remogliflozin, the active SGLT2 inhibitor. Remogliflozin undergoes further metabolism by CYP enzymes directly yielding GSK279782 and GSK333081, and non-CYP mediated pathways such as glucosidases and UDP-glucuronosyltransferases ultimately yielding glucuronide metabolites. Remogliflozin and GSK279782 are both potent SGLT2 inhibitors (in vitro Ki values 12 $\mathrm{nM}$ ) [15] and account for the majority of the pharmacological activity in vivo [25]. Of the four non-glucuronide analytes, remogliflozin is the major circulating metabolite, with GSK279782 being 16-22\% of remogliflozin exposure. In contrast, GSK333081 has an in vitro Ki of 30 $\mathrm{nM}$ and exposures of $\sim 6 \%$ of remogliflozin; thus, it is not expected that GSK333081 contributes significantly to the in vivo pharmacological activity in humans. Remogliflozin etabonate does not have pharmacological activity and is $<2 \%$ of the remogliflozin exposure [15]. The final end products of remogliflozin metabolism are three inactive glucuronide conjugates (GSK1997711, GSK1997714, GSK355993), which are eliminated almost exclusively in the urine [25]. GSK1997711 is the largest circulating metabolite, representing $48 \%$ of the dose.

\section{ATP-Binding Cassette (ABC) and Solute Carrier (SLC) transport inhibition assays}

The inhibition of Pgp (concentration range 0.1 to $100 \mu \mathrm{M}$ ) by remogliflozin etabonate, remogliflozin, GSK279782, and GSK333081 was assessed by determining the $\mathrm{B} \rightarrow \mathrm{A}$ transport of $\left[{ }^{3} \mathrm{H}\right]$-digoxin across MDCKII-MDR1 monolayers. Neither remogliflozin etabonate,

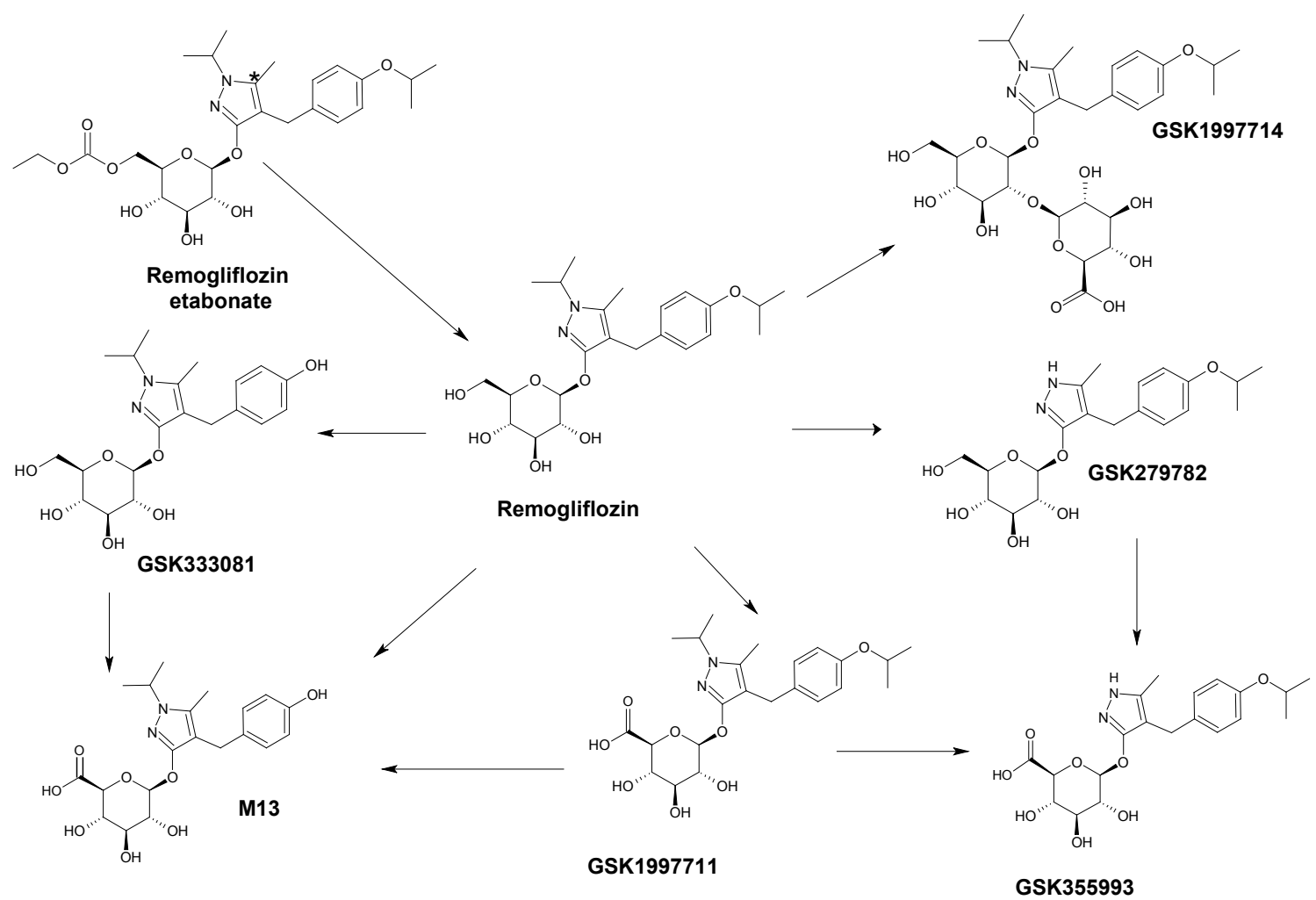

Figure 1: Structure and human metabolic pathway for Remogliflozin Etabonate. The * indicates the position of the ${ }^{14} \mathrm{C}$ label. 
Citation: Polli JW, Humphreys JE, Harmon KA, Webster LO, Reese MJ, et al. (2012) Assessment of Remogliflozin Etabonate, a Sodium-Dependent Glucose Co-Transporter-2 Inhibitor, as a Perpetrator of Clinical Drug Interactions: A Study on Drug Transporters and Metabolic Enzymes. J Diabetes Metab 3:200. doi:10.4172/2155-6156.1000200

Page 5 of 8

\begin{tabular}{|c|c|c|c|c|c|}
\hline \multirow[t]{2}{*}{ Transporter } & \multicolumn{4}{|c|}{$\mathrm{IC}_{50}(\mu \mathrm{M})$} & \multirow[t]{2}{*}{ Probe Substrate } \\
\hline & Remogliflozin Etabonate & Remogliflozin & GSK279782 & GSK333081 & \\
\hline Pgp & $>100$ & $>100$ & $>100$ & $>100$ & {$\left[{ }^{3} \mathrm{H}\right]$-digoxin } \\
\hline OATP1B1 & $5.3(1.1)^{a}$ & $25(2.3)$ & $14(1.5)$ & NT & {$\left[{ }^{3} \mathrm{H}\right]$-estradiol $17 \beta-\mathrm{D}$-glucuronide } \\
\hline OCT1 & $43.4(3.7)$ & $38.6(1.6)$ & $>100$ & $>100$ & {$\left[{ }^{14} \mathrm{C}\right]$-tetraethylammonium } \\
\hline ОСТ3 & $>100$ & $>100$ & $>100$ & $>100$ & {$\left[{ }^{3} \mathrm{H}\right]$-histamine } \\
\hline
\end{tabular}

aData are the mean ( \pm standard deviation) from triplicate wells.

NT: Not Tested

Table 1: Inhibition of Human ABC and SLC Transporters by Remogliflozin etabonate, Remogliflozin and Metabolites.

\begin{tabular}{|c|c|c|c|c|c|}
\hline \multirow[t]{2}{*}{ Transporter } & \multicolumn{4}{|c|}{$\%$ Control Activity ${ }^{\text {a }}$} & \multirow[t]{2}{*}{ Probe Substrate } \\
\hline & Remogliflozin Etabonate & Remogliflozin & GSK279782 & GSK333081 & \\
\hline OAT 1 & $102(5.2)$ & $101(4.1)$ & $105(2.5)$ & $107(5.4)$ & {$\left[{ }^{14} \mathrm{C}\right]-p$-aminohippuric acid } \\
\hline OAT 2 & $122(3.4)$ & $84.3(3.5)$ & $87.2(1.4)$ & $82.5(1.5)$ & {$\left[{ }^{3} \mathrm{H}\right]$-prostaglandin $\mathrm{F} 2 \alpha$} \\
\hline OAT 3 & $84.4(1.9)$ & $110(0.6)$ & $112(3.7)$ & $115(1.9)$ & {$\left[{ }^{3} \mathrm{H}\right]$-estrone sulfate } \\
\hline OAT 4 & $96.3(1.5)$ & $99.6(2.1)$ & $89.5(0.5)$ & $93.0(2.0)$ & {$\left[{ }^{3} \mathrm{H}\right]$-estrone sulfate } \\
\hline OCT 1 & $44.6(4.6)$ & $84.0(3.2)$ & $74.0(3.1)$ & $72.2(9.8)$ & {$\left[{ }^{14} \mathrm{C}\right]$-tetraethylammonium } \\
\hline OCT 2 & $105(2.1)$ & $107(3.5)$ & $98.3(7.2)$ & $113(0.7)$ & {$\left[{ }^{14} \mathrm{C}\right]$-tetraethylammonium } \\
\hline OCT $2 \mathrm{~A}$ & $98.9(1.6)$ & $112(3.2)$ & $112(1.5)$ & $102(2.7)$ & {$\left[{ }^{14} \mathrm{C}\right]$-tetraethylammonium } \\
\hline OCT 3 & $73.8(3.6)$ & $62.9(1.7)$ & $87.5(2.9)$ & $69.0(0.7)$ & {$\left[{ }^{3} \mathrm{H}\right]$-histamine } \\
\hline URAT1 & $106(2.6)$ & $112(2.5)$ & $111(4.4)$ & $112(2.5)$ & {$\left[{ }^{14} \mathrm{C}\right]$-uric acid } \\
\hline
\end{tabular}

aData are the mean ( \pm standard deviation) from triplicate well from a single concentration screening experiment. Inhibition of more than $20 \%$ was considered notable and

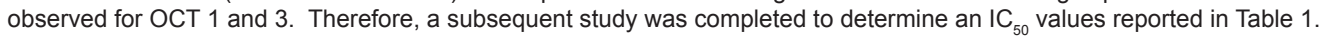

Table 2: Inhibition of Human Solute Carriers by $30 \mu \mathrm{M}$ Remogliflozin etabonate, Remogliflozin and Metabolites.

\begin{tabular}{|c|c|c|c|c|c|c|}
\hline \multirow[t]{2}{*}{ CYP Enzyme } & \multicolumn{6}{|c|}{ Direct $\mathrm{IC}_{50}(\mu \mathrm{M})^{\mathrm{a}}$} \\
\hline & Remogliflozin ${ }^{b}$ & GSK279782 b & GSK333081 c & GSK1997711 c & GSK1997714 c & GSK355993 c \\
\hline $1 \mathrm{~A} 2$ & $>100$ & $>100$ & $>100$ & $>300$ & $>300$ & $>300$ \\
\hline $2 A 6$ & $>100$ & $>100$ & $N T^{d}$ & NT & NT & NT \\
\hline 2B6 & $>100$ & $>100$ & NT & NT & NT & NT \\
\hline $2 \mathrm{C} 8$ & $>100$ & $>100$ & NT & NT & NT & NT \\
\hline $2 \mathrm{C} 9$ & $>100$ & $>100$ & $>100$ & $>300$ & $>300$ & $>300$ \\
\hline 2C19 & $>100$ & $>100$ & $>100$ & $>300$ & $>300$ & $>300$ \\
\hline 2D6 & $>100$ & $>100$ & $>100$ & $>300$ & $>300$ & $>300$ \\
\hline $3 \mathrm{~A} 4$ & $>100$ & $>100$ & $>100$ & $>300$ & $>300$ & $>300$ \\
\hline
\end{tabular}

aDirection inhibition studies added the inhibitor with probe substrate together. Assays were initiated with addition of cofactor.

${ }^{\mathrm{b} C Y P}$ HPLC-LC/MS Inhibition method with probes substrates: CYP 1A2 Phenacetin; 2A6 - Coumarin; 2B6 - Buproprion; 2 C8 - Rosiglitazone; 2C9 - Diclofenac; 2C19 Mephenytoin; 2D6 - Bufuraol; 3A4 - Atorvastatin, Midazolam, and Nifedipine

${ }^{\circ}$ CYP Flourescence Inhibition Method with probe substrates: CYP 1A2- ethoxyresorufin; 2C9 - 7-methoxy-4-trifluromethylcoumarin-3-acetic acid; 2C19 - 3-butyryl-7methoxycoumarin; 2D6 - 4-methylaminomethyl-7-methoxycoumarin; 3A4 - diethoxyfluorescein and 7-benzyloxyquinoline

${ }^{\mathrm{d}} \mathrm{NT}=$ not tested

Table 3: Inhibition of Cytochrome P450 Enzymes by Remogliflozin etabonate, Remogliflozin and Metabolites.

remogliflozin, nor the metabolites were inhibitors of Pgp $\left(\mathrm{IC}_{50}\right.$ values $>100 \mu \mathrm{M}$; Table 1). In contrast, remogliflozin etabonate, remogliflozin, and GSK279782 inhibited the OATP1B1-mediated uptake of $\left[{ }^{3} \mathrm{H}\right]$ estradiol 17 $\beta$-D-glucuronide $\left(\left[{ }^{3} \mathrm{H}\right]-\mathrm{EG}\right)$ in the CHO-OATP1B1 cell line. The $\mathrm{IC}_{50}$ values were 5.3, 25, and $14 \mu \mathrm{M}$ respectively for remogliflozin etabonate, remogliflozin, and GSK279782 (Table 1).

The inhibitory effect of remogliflozin etabonate, remogliflozin, GSK279782 and GSK333081 on a panel of human renal transporters was investigated in S2 cells stably expressing organic anion transporter 1 (OAT1), OAT2, OAT3, or OAT4, the organic cation transporter 1 (OCT1), OCT2 (isoform a), OCT2-A (isoform b) or OCT3, and HEK293 cells expressing urate transporter 1 (URAT1). For each transporter, transfected cells were initially incubated with the radiolabeled substrate in the absence or presence of $30 \mu \mathrm{M}$ of remogliflozin etabonate, remogliflozin, GSK279782 or GSK333081 (Table 2). Of the nine transporters tested, only OCT1 and OCT3 showed $>20 \%$ inhibition by remogliflozin etabonate, remogliflozin, or the metabolites. Due to this notable inhibition, a follow up study was completed to determine $\mathrm{IC}_{50}$ values against OCT1 and OCT3. Remogliflozin etabonate and remogliflozin inhibited OCT1 with $\mathrm{IC}_{50}$ values of 43.4 and $38.6 \mu \mathrm{M}$, respectively, while GSK29782 and GSK333081 had IC $_{50}$ values $>100 \mu \mathrm{M}$ (Table 1). All four compounds had $\mathrm{IC}_{50}$ values $>100 \mu \mathrm{M}$ for OCT3, demonstrating weak inhibition of this transporter. Finally, the three circulating glucuronide metabolites GSK1997711, GSK1997714 and GSK355993 were tested as OAT1, 3 and 4 inhibitors $(0.1$ to $300 \mu \mathrm{M})$ as they are eliminated in the urine [25]. None of these compounds inhibited the OAT transporters (data not shown).

\section{CYP inhibition assays}

The inhibition of CYP enzymes by remogliflozin and GSK279782 was assessed using a LC/MS based methods (CYP 1A2, 2A6, 2B6, 2C8, 2C9, 2C19, 2D6 and 3A4) while the metabolites (GSK3333081, GSK1997711, GSK1997714, and GSK355993) were assessed using fluorescence based 
Citation: Polli JW, Humphreys JE, Harmon KA, Webster LO, Reese MJ, et al. (2012) Assessment of Remogliflozin Etabonate, a Sodium-Dependent Glucose Co-Transporter-2 Inhibitor, as a Perpetrator of Clinical Drug Interactions: A Study on Drug Transporters and Metabolic Enzymes. J Diabetes Metab 3:200. doi:10.4172/2155-6156.1000200

Page 6 of 8

\begin{tabular}{|l|l|l|l|}
\hline \multirow{2}{*}{ Treatment } & \multicolumn{2}{l|}{$\begin{array}{l}\text { Mean mRNA Expression } \\
\text { (Mean ratio of treated over control a) }\end{array}$} \\
& \multicolumn{3}{|l|}{} \\
\cline { 2 - 4 } & CYP1A2 & CYP2B6 & CYP3A4 \\
\hline $1 \mu \mathrm{M}$ Remogliflozin & $1.1 \pm 0.16$ & $1.0 \pm 0.057$ & $0.84 \pm 0.19$ \\
\hline $10 \mu \mathrm{M}$ Remogliflozin & $1.7 \pm 1.4$ & $1.4 \pm 0.18$ & $1.7 \pm 0.26$ \\
\hline $100 \mu \mathrm{M}$ Remogliflozin & $1.6 \pm 0.38$ & $2.2 \pm 0.72$ & $5.0 \pm 2.4$ \\
\hline Prototypical Inducer ${ }^{\mathrm{b}}$ & $110 \pm 83$ & $\begin{array}{l}8.6 \pm 1.2(\mathrm{~PB}) \\
14 \mu 2.8 \text { (Rif) }\end{array}$ & $50 \pm 32$ \\
\hline
\end{tabular}

aControls are defined as $0.1 \%(\mathrm{v} / \mathrm{v})$ DMSO; Values are expressed as a mean \pm standard deviation of 3 human hepatocyte preparations. The criterion for notable induction is a response by the test compound that is greater than $20 \%$ of the response seen by the prototypical inducer

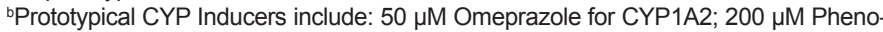
barbital (PB) for CYP2B6; $50 \mu$ M Rifampicin (Rif) for CYP3A4 and CYP2B6

Table 4: Induction of Cytochrome P450 mRNA by Remogliflozin in Human Hepatocytes.

\begin{tabular}{|c|c|c|c|c|c|c|c|c|}
\hline \multirow[b]{2}{*}{ Tissue } & \multicolumn{4}{|c|}{$\begin{array}{l}\text { Concentration ( } \mu \mathrm{g} \\
\text { equivalents/g tissue) }\end{array}$} & \multicolumn{4}{|c|}{ Tissue-to-Blood Ratio } \\
\hline & $0.25 \mathrm{hr}^{\mathrm{a}}$ & $1 \mathrm{hr}$ & $4 \mathrm{hr}$ & $24 \mathrm{hr}$ & $0.5 \mathrm{hr}$ & $4 \mathrm{hr}$ & $8 \mathrm{hr}$ & $24 \mathrm{hr}$ \\
\hline Blood & 2.92 & 3.56 & 1.02 & 0.15 & 1.00 & 1.00 & 1.00 & 1.00 \\
\hline Brain & 0.24 & 0.53 & 0.14 & $\mathrm{BLQ}^{\mathrm{b}}$ & 0.08 & 0.15 & 0.14 & NC \\
\hline Harderian Gland & 1.25 & 3.73 & 1.24 & 0.31 & 0.43 & 1.05 & 1.21 & 2.10 \\
\hline Heart & 2.64 & 2.58 & 0.72 & 0.09 & 0.90 & 0.76 & 0.70 & 0.64 \\
\hline Kidney & 11.0 & 14.1 & 3.96 & 0.41 & 3.75 & 3.97 & 3.87 & 2.79 \\
\hline Liver & 32.8 & 16.3 & 9.06 & 1.72 & 11.2 & 4.57 & 8.87 & 11.7 \\
\hline Muscle & 0.75 & 1.65 & 0.47 & $B L Q$ & 0.26 & 0.46 & 0.46 & NC \\
\hline
\end{tabular}

${ }^{a} \mathrm{n}=1$ animal per time point

bAbbreviations: BLQ: Below Limit of Quantification; NC = Not Calculated

Table 5: Tissue Concentrations and Tissue-to-Blood Ratios of Radioactivity in Male Rats After A Single Oral Administration of $25 \mathrm{mg} / \mathrm{kg}$ [14C]-Remogliflozin etabonate.

methods (CYP 1A2, 2C9, 2C19, 2D6 and 3A4). Remogliflozin etabonate was not tested due to its instability in microsomes both in the presence or absence of NADPH. Remogliflozin, GSK279782 and all of the other metabolites were not inhibitors of any of the CYP enzymes tested ( $\mathrm{IC}_{50}$ values $>100 \mu \mathrm{M}$; Table 3). As well, remogliflozin and GSK279782 were not metabolism dependent inhibitors (data not shown).

\section{CYP induction assays}

The CYP induction potential of remogliflozin etabonate, remogliflozin and GSK279782 were assessed using a pregnane X receptor (PXR) assay and the potential of remogliflozin to induce CYP mRNA was assessed using human hepatocytes. Remogliflozin etabonate $(0.01$ to $10 \mu \mathrm{M})$ activated PXR in vitro to $71 \%$ compared to the maximum of the positive control (10 $\mu \mathrm{M}$ rifampicin). In contrast, remogliflozin and GSK279782 (0.01 to $10 \mu \mathrm{M})$ did not activate PXR ( $<15 \%$ of control). Because of the activation seen by the prodrug remogliflozin etabonate, remogliflozin was investigated for its ability to induce CYP mRNA in human hepatocytes; remogliflozin etabonate was not tested due to its instability in the cell culture conditions. After incubation for 48 hours with remogliflozin $(1,10$ or $100 \mu \mathrm{M})$, there was no notable induction ( $<20 \%$ of prototypical inducer) of CYP1A2 or 3A4 mRNA (Table 4). There was a small increase in CYP3A4 mRNA in one of three human hepatocytes preparations as reflected in the 5 -fold change and associated large standard deviation. However, the mean 5 -fold change was well below the 50-fold induction observed with 50 $\mu \mathrm{M}$ rifampicin, a prototypical CYP3A4 inducer. However, at $100 \mu \mathrm{M}$, remogliflozin did show a small induction of CYP2B6 mRNA $(\sim 26 \%$ of the response seen with phenobarbarbital $(200 \mu \mathrm{M})$, a prototypical inducer of the CYP2B6 gene).

\section{Whole-body autoradiography in rats}

The tissue distribution of $\left[{ }^{14} \mathrm{C}\right]$-remogliflozin etabonate was determined in male rats by using whole-body autoradiography at 0.25 , $1,4,24$ hours, 3 and 28 days after oral administration ( $\mathrm{n}=1$ animal per time point). The absorption of radioactivity following a single oral dose of $25 \mathrm{mg} / \mathrm{kg}\left[{ }^{14} \mathrm{C}\right]$-remogliflozin etabonate yielded widely distributed radioactivity into tissues with the exception of brain and was cleared from most tissues by 24 hours post dose, mainly by biliary and renal elimination (Figure 2 and Table 5). Tissues with the highest radioactivity included the liver, kidney, and harderian gland. Only low levels of radioactivity were detected in the central nervous system (CNS) at any time (brain-to-plasma ratios $<0.15$ ).

\section{Discussion}

SGLT2 inhibitors are a new class of potential anti-diabetic drugs $[6,8,12]$. A number of small molecule SGLT2 inhibitors are/have been under clinical development, including the first orally absorbable SGLT inhibitor T-1095 [26], sergliflozin etabonate (GW868682) [27,28], remogliflozin etabonate (GSK189075) [14], and dapagliflozin (BMS512148) $[29,30]$. Remogliflozin etabonate is a novel member of the betaD-glucopyranoside class of SGLT2 inhibitors with in vitro Ki values near $12 \mathrm{nM}$ [15]. In addition, as large (molecular weight range 408 to 523) and lipophilic (clogP range $=1.7$ to 2.7 ) molecules, remogliflozin etabonate, remogliflozin and GSK278782 are typical of drugs that interact with $\mathrm{ABC}$ efflux and SLC transporters [31]. It was therefore of interest to investigate the interaction of remogliflozin etabonate and its metabolites with drug transporters to assess the potential for drug interactions.

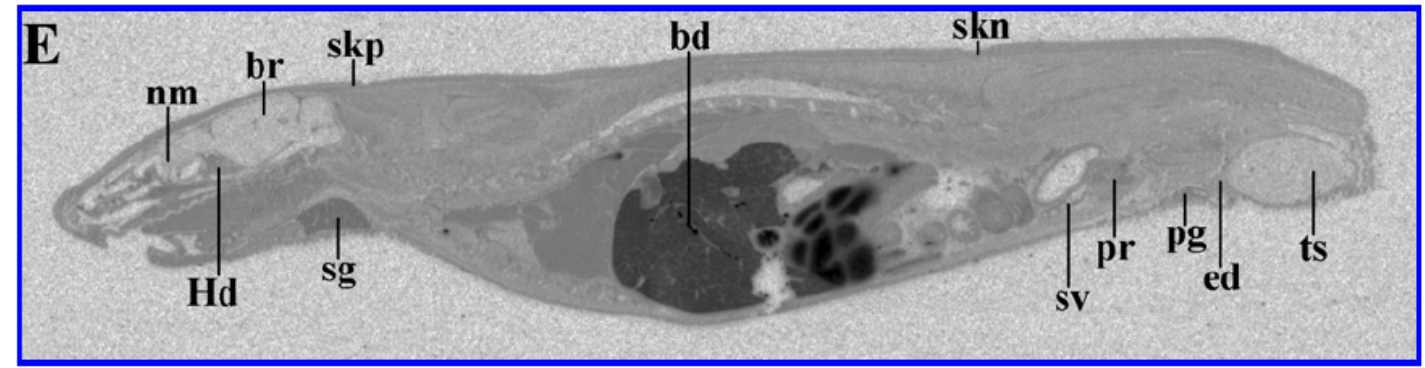

Figure 2: Whole-body autoradiogram of a male rat 4 hours after a single oral administration of $\left[{ }^{14} \mathrm{C}\right]$-Remogliflozin etabonate at a dose of $10 \mathrm{mg} / \mathrm{kg}$ in $0.5 \%$ (w/v) aqueous hydroxypropyl methyl cellulose containing $0.1 \%(\mathrm{v} / \mathrm{v})$ Tween 80 . Tissue processing and image analysis were completed as described in Material and Methods. Digital images were obtained by phosphorimaging. Abbreviations: bf- brown fat; ed- epdidymis; Hd- harderian gland; nm- nasal mucosa; pg- preputial gland; pr- prostate; sg- salivary gland; skn- non-pigmented skin; skp- pigmented skin; sv- seminal vesicles; ts- testis 
Citation: Polli JW, Humphreys JE, Harmon KA, Webster LO, Reese MJ, et al. (2012) Assessment of Remogliflozin Etabonate, a Sodium-Dependent Glucose Co-Transporter-2 Inhibitor, as a Perpetrator of Clinical Drug Interactions: A Study on Drug Transporters and Metabolic Enzymes. J Diabetes Metab 3:200. doi:10.4172/2155-6156.1000200

Remogliflozin etabonate, remogliflozin and GSK279782 were inhibitors of OATP1B1 ( $\mathrm{IC}_{50}$ values of 5.3, 25 and $14 \mu \mathrm{M}$, respectively), and remogliflozin etabonate and remogliflozin were inhibitors of OCT1 ( $\mathrm{IC}_{50}$ values of 43 and $39 \mu \mathrm{M}$, respectively). In contrast, GSK333081 was not an inhibitor of OATP or OCT1. Further, remogliflozin etabonate, remogliflozin, GSK279782 and GSK333081 were not inhibitors of Pgp, OCT2, OCT2A, OCT3, OAT1, OAT2, OAT3, OAT4 or URAT1. These $\mathrm{IC}_{50}$ values for OATP1B1 and OCT1 inhibition are much higher than the range of peak plasma concentrations following a $100 \mathrm{mg}$ BID dose [14] (remogliflozin etabonate $=0.03 \mu \mathrm{M}$ or $16.3 \mathrm{ng} / \mathrm{mL}$; remogliflozin $=0.95 \mu \mathrm{M}$ or $427 \mathrm{ng} / \mathrm{mL}$; GSK279782 $=0.13 \mu \mathrm{M}$ or $54.8 \mathrm{ng} / \mathrm{mL}$ ) suggesting little potential for transporter-mediated drug interactions, even when taking into consideration the potential 3- to 12-fold higher total drug and metabolite burden in tissues such as the kidney and liver as observed in the whole-body autoradiography study (Figure 2 and Table 5).

Remogliflozin etabonate, remogliflozin and its metabolites were also tested for in vitro inhibition or induction interaction with CYP enzymes. Remogliflozin and GSK279782 were not direct or mechanism-based inhibitors of eight CYP enzymes (Table 3). Further, GSK333081 and the three circulating glucuronide metabolites were also not direct inhibitors of CYP enzymes. Remogliflozin etabonate, but not remogliflozin or GSK279782, activated PXR in vitro with some potency (71\% of the prototypical inhibitor response when tested up to 10 clinical Cmax for remogliflozin M). This observation was followed up with a human hepatocytes study using remogliflozin as the etabonate prodrug was not stable in the cell culture conditions. Remogliflozin (up to $100 \mu \mathrm{M}$ ) did not induce CYP3A4 or 1A1 mRNA in human hepatocytes. However a small increase was noted for CYP2B6 mRNA. This response was only $26 \%$ of the prototypical inducer phenobarbital and was observed only at the high dose tested $(100 \mu \mathrm{M})$, which is 100-times higher than the observed clinical $\mathrm{C}_{\max }$ for remogliflozin following $100 \mathrm{mg}$ BID dosing. Further the response was less than $20 \%$ of the response of rifampicin, an inducer of both CYP2B6 and 3A4. Overall, the CYP inhibition and induction data, along with the clinical observations to date $[14,32]$, suggest that remogliflozin etabonate can be dosed with other drugs metabolized by CYP enzymes such as sulfonylureas, calcium channel blockers and statins without concern of a pharmacokinetic drug interaction.

The characterization of the interactions of remogliflozin etabonate with transporters and drug metabolizing enzymes, together with other clinical data, is a first step towards understanding the drug interaction potential between remogliflozin etabonate and other therapeutic agents. Many T2DM patients take multiple anti-diabetic drugs, as well as treatments for hypertension, heart failure and dyslipidemia. Such agents often include metformin, DPP-IV inhibitors, thiazolidinediones, sulfonylureas, digoxin and statins. The importance of understanding the potential inhibition of transporters and enzymes is apparent with the possible co-administration of these drugs. For example, metformin, digoxin, rosuvastatin, and sitagliptin are not (extensively) metabolized, but drug transporters have key roles in the disposition or efficacy of these compounds (see drugs labels at http://www.accessdata.fda.gov/ scripts/cder/drugsatfda/index.cfm). Metformin is a substrate for OCT1 and 2 [33,34], rosuvastatin is a substrate for OATP1B1 [35], digoxin is a Pgp substrate [36] and sitagliptin a substrate for OAT3 [37]. As remogliflozin etabonate and its metabolites are not strong inhibitors of transporters, there are expected to be no drug interactions between remogliflozin etabonate and these agents. Indeed, a clinical study with metformin and remogliflozin etabonate confirmed that there was no pharmacokinetic or dynamic interaction between these two anti-diabetic medicines [32]. Similarly, there are a number of expected coadministered drugs such as simvastatin, rosiglitazone and glimepiride that undergo extensive CYP-mediated metabolism [38-40]. As remogliflozin etabonate and its metabolites are not CYP inhibitors or inducers, it follows that interactions between these CYP substrates and remogliflozin etabonate are not expected.

In conclusion, remogliflozin etabonate and remogliflozin inhibit a number of SLC transporters (OATP1B1 and OCT) that are involved in the disposition of drugs used in the treatment of diabetes or its associated co-morbidities. The $\mathrm{IC}_{50}$ values are significantly higher than the expected peak plasma concentrations of remogliflozin following a $100 \mathrm{mg}$ BID dosing schedule, supporting that the risk of drug interactions for other drugs when administered with remogliflozin etabonate and remogliflozin is low. Further, remogliflozin etabonate and its metabolites did not inhibit a number of other ABC and SLC transporters or CYP enzymes. These in vitro investigations along with pharmacokinetic studies in healthy volunteers and subjects with T2DM provide a mechanistic basis for elucidating clinical drug interactions by remogliflozin etabonate. This information has been used to guide the design of clinical studies with remogliflozin etabonate.

\section{References}

1. Stratton IM, Adler AI, Neil HA, Matthews DR, Manley SE, et al. (2000) Association of glycaemia with macrovascular and microvascular complications of type 2 diabetes (UKPDS 35): prospective observational study. BMJ 321: 405-412.

2. Turner RC, Cull CA, Frighi V, Holman RR (1999) Glycemic control with diet sulfonylurea, metformin, or insulin in patients with type 2 diabetes mellitus: progressive requirement for multiple therapies (UKPDS 49). UK Prospective Diabetes Study (UKPDS) Group. JAMA 281: 2005-2012.

3. Nathan DM, Cleary PA, Backlund JY, Genuth SM, Lachin JM, et al. (2005) Intensive diabetes treatment and cardiovascular disease in patients with type 1 diabetes. N Engl J Med 353: 2643-2653.

4. Nathan DM, Buse JB, Davidson MB, Heine RJ, Holman RR, et al. (2006) Management of hyperglycemia in type 2 diabetes: A consensus algorithm for the initiation and adjustment of therapy: a consensus statement from the American Diabetes Association and the European Association for the Study of Diabetes. Diabetes Care 29: 1963-1972.

5. Inzucchi SE, Bergenstal RM, Buse JB, Diamant M, Ferrannini E, et al. (2012) Management of hyperglycaemia in type 2 diabetes: a patient-centered approach. Position statement of the American Diabetes Association (ADA) and the European Association for the Study of Diabetes (EASD). Diabetologia 55 1577-1596.

6. Papazafiropoulou AK, Kardara MS, Pappas SI (2011) Challenges for the treatment of diabetes mellitus.. Recent Pat Endocr Metab Immune Drug Discov 5: 203-209.

7. Washburn WN (2009) Development of the renal glucose reabsorption inhibitors: a new mechanism for the pharmacotherapy of diabetes mellitus type 2 . J Med Chem 52: 1785-1794.

8. Idris I, Donnelly R (2009) Sodium-glucose co-transporter-2 inhibitors: an emerging new class of oral antidiabetic drug. Diabetes Obes Metab 11: 79-88.

9. Abdul-Ghani MA, Norton L, DeFronzo RA (2012) Efficacy and safety of SGLT2 inhibitors in the treatment of type 2 diabetes mellitus. Curr Diab Rep 12:230238

10. Bakris GL, Fonseca VA, Sharma K, Wright EM (2009) Renal sodium-glucose transport: role in diabetes mellitus and potential clinical implications. Kidney Int 75: $1272-1277$.

11. Nishimura M, Naito S (2005) Tissue-specific mRNA expression profiles of human ATP-binding cassette and solute carrier transporter superfamilies. Drug Metab Pharmacokinet. 20: 452-477.

12. Bays $H$ (2009) From victim to ally: the kidney as an emerging target for the treatment of diabetes mellitus. Curr Med Res Opin 25: 671-681. 
Citation: Polli JW, Humphreys JE, Harmon KA, Webster LO, Reese MJ, et al. (2012) Assessment of Remogliflozin Etabonate, a Sodium-Dependent Glucose Co-Transporter-2 Inhibitor, as a Perpetrator of Clinical Drug Interactions: A Study on Drug Transporters and Metabolic Enzymes. J Diabetes Metab 3:200. doi:10.4172/2155-6156.1000200

Page 8 of 8

13. Jabbour SA, Goldstein BJ (2008) Sodium glucose co-transporter 2 inhibitors: blocking renal tubular reabsorption of glucose to improve glycaemic control in patients with diabetes. Int J Clin Pract 62:1279-1284

14. Dobbins RL, O'Connor-Semmes R, Kapur A, Kapitza C, Golor G, et al. (2012) Remogliflozin etabonate, a selective inhibitor of the sodium-dependent transporter 2 reduces serum glucose in type 2 diabetes mellitus patients. Diabetes Obes Metab 14: 15-22.

15. Fujimori Y, Katsuno K, Nakashima I, Ishikawa-Takemura Y, Fujikura H et al. (2008) Remogliflozin etabonate, in a novel category of selective low-affinity sodium glucose cotransporter (SGLT2) inhibitors, exhibits antidiabetic efficacy in rodent models. J Pharmacol Exp Ther 327: 268-276.

16. Rautio J, Humphreys JE, Webster LO, Balakrishnan A, Keogh JP, et al. (2006) In vitro p-glycoprotein inhibition assays for assessment of clinical drug interaction potential of new drug candidates: a recommendation for probe substrates. Drug Metab Dispos 34: 786-792.

17. Polli JW, Humphreys JE, Harmon KA, Castellino S, O'Mara MJ, et al. (2008) The role of efflux and uptake transporters in [N-\{3-chloro-4-[(3-fluorobenzyl) oxy]phenyl\}-6-[5-(\{[2-(methylsulfonyl)ethyl]amino\}methyl)-2-furyl]-4-quinazolinamine (GW572016, lapatinib) disposition and drug interactions. Drug Metab Dispos 36: 695-701.

18. Takeda M, Khamdang S, Narikawa S, Kimura H, Kobayashi Y, et al. (2002) Human organic anion transporters and human organic cation transporters mediate renal antiviral transport. J Pharmacol Exp Ther 300: 918-924.

19. Shardlow CE, Generaux GT, MacLauchlin CC, Pons N, Skordos KW, et al (2011) Utilizing drug-drug interaction prediction tools during drug development enhanced decision making based on clinical risk. Drug Metab Dispos 39: 2076 2084.

20. Reese MJ, Wurm RM, Muir KT, Generaux GT, St John-Williams L, et al. (2008) An in vitro mechanistic study to elucidate the desipramine/bupropion clinical drug-drug interaction. Drug Metab Dispos 36: 1198-1201.

21. Lehmann JM, McKee DD, Watson MA, Willson TM, Moore JT et al. (1998) The human orphan nuclear receptor PXR is activated by compounds that regulate CYP3A4 gene expression and cause drug interactions. J Clin. Invest 102: 1016-1023.

22. Polli JW, Jarrett JL, Studenberg SD, Humphreys JE, Dennis SW, et al. (1999) Role of P-glycoprotein on the CNS disposition of amprenavir (141W94), an HIV protease inhibitor. Pharm Res 16: 1206-1212.

23. Solon EG, Balani SK, Luo G, Yang TJ, Haines PJ, et al. (2002) Interaction of ritonavir on tissue distribution of a $[(14) c] L$-valinamide, a potent human immunodeficiency virus-1 protease inhibitor, in rats using quantitative whole-body autoradiography. Drug Metab Dispos 30: 1164-1169.

24. Solon EG, Balani SK, Lee FW (2002) Whole-body autoradiography in drug discovery. Curr Drug Metab 3: 451-462.

25. Sigafoos JF, Bowers GD, Castellino S, Culp AG, Wagner DS, et al. (2012) The Absorption, Metabolism, and Excretion of Remogliflozin Etabonate, a Novel Sodium-Dependent Glucose Co-Transporter-2 Inhibitor, in Humans: Evidence from In vitro Studies and Clinical Mass Balance and Ketoconazole Drug Interaction Studies. Drug Metab Dispos. (Submitted).

26. Tsujihara K, Hongu M, Saito K, Kawanishi H, Kuriyama K, et al. (1999) Na(+)glucose cotransporter (SGLT) inhibitors as antidiabetic agents. 4. Synthesis and pharmacological properties of 4'-dehydroxyphlorizin derivatives substituted on the B ring. J Med Chem 42: 5311-5324.

27. Katsuno K, Fujimori Y, Takemura Y, Hiratochi M, Itoh F, et al. (2007) Sergliflozin a novel selective inhibitor of low-affinity sodium glucose cotransporter (SGLT2), validates the critical role of SGLT2 in renal glucose reabsorption and modulates plasma glucose level. J Pharmacol Exp Ther 320: 323-330.

28. Hussey EK, Dobbins RL, Stoltz RR, Stockman NL, O'Connor-Semmes RL, et al. (2010) Multiple-dose pharmacokinetics and pharmacodynamics of sergliflozin etabonate, a novel inhibitor of glucose reabsorption, in healthy overweight and obese subjects: a randomized double-blind study. J Clin Pharmacol 50: 636-646

29. Ellsworth BA, Meng W, Patel M, Girotra RN, Wu G, et al. (2008) Aglycone exploration of $\mathrm{C}$-arylglucoside inhibitors of renal sodium-dependent glucose transporter SGLT2. Bioorg Med Chem Lett 18: 4770-4773.

30. Meng W, Ellsworth BA, Nirschl AA, McCann PJ, Patel M, et al. (2008) Discovery of dapagliflozin: a potent, selective renal sodium-dependent glucose cotrans- porter 2 (SGLT2) inhibitor for the treatment of type 2 diabetes. J Med Chem 51: $1145-1149$

31. Chang C, Swaan PW (2006) Computational approaches to modeling drug transporters. Eur J Pharm Sci 27: 411-424.

32. Hussey EK, O'Connor-Semmes R, Tao W, Poo JL, Dobbins RL (2009) Safety, pharmacokinetics and pharmacodynamics of remogliflozin etabonate (SGLT2 inhibitor) and metformin when co-administered in type 2 diabetes mellitus patients. Diabetes 57: 582.

33. Shu Y, Brown C, Castro RA, Shi RJ, Lin ET, et al. (2008) Effect of genetic variation in the organic cation transporter $1, \mathrm{OCT} 1$, on metformin pharmacokinetics. Clin Pharmacol Ther 83: 273-280.

34. Song IS, Shin HJ, Shim EJ, Jung IS, Kim WY, et al. (2008) Genetic variants of the organic cation transporter 2 influence the disposition of metformin. Clin Pharmacol Ther 84: 559-562.

35. Kitamura S, Maeda K, Wang Y, Sugiyama Y (2008) Involvement of multiple transporters in the hepatobiliary transport of rosuvastatin. Drug Metab Dispos 36: 2014-2023.

36. Tsujimoto M, Dan Y, Hirata S, Ohtani H, Sawada Y (2008) Influence of SLCO1B3 gene polymorphism on the pharmacokinetics of digoxin in terminal renal failure. Drug Metab Pharmacokinet 23: 406-411.

37. Chu XY, Bleasby K, Yabut J, Cai X, Chan GH, et al. (2007) Transport of the dipeptidyl peptidase-4 inhibitor sitagliptin by human organic anion transporter 3 , organic anion transporting polypeptide $4 \mathrm{C} 1$, and multidrug resistance P-glycoprotein. J Pharmacol Exp Ther 321: 673-683.

38. Deeks ED, Keam SJ (2007) Rosiglitazone: a review of its use in type 2 diabetes mellitus. Drugs 67: 2747-2779.

39. Iwakawa S, Miyashita K, Hashimoto Y, Kuroda T (2006) Effect of glimepiride and glibenclamide on S-warfarin 7-hydroxylation by human liver microsomes recombinant human CYP2C9.1 and CYP2C9.3. Biol Pharm Bull 29: 1983-1985.

40. Neuvonen PJ, Backman JT, Niemi M (2008) Pharmacokinetic comparison of the potential over-the-counter statins simvastatin, lovastatin, fluvastatin and pravastatin. Clin Pharmacokinet 47: 463-474. 